\title{
ANÁLISIS SISTÉMICO IN SILICO DE LA EXPRESIÓN DIFERENCIAL DE GENES LOCALIZADOS EN LA REGIÓN CRÍTICA DEL SÍNDROME DE DOWN (DSCR) EN EL CEREBRO HUMANO
}

\author{
Julio César Montoya Villegas Ph.D. ${ }^{1}$, Ángela Peña González B.Sc. ${ }^{2}$, \\ José María Satizábal Soto MD, M.Sc ${ }^{3}$ y Felipe García-Vallejo Ph. $D^{4}$ \\ ${ }^{1}$ Profesor asociado Facultad de Ciencias Básicas, Universidad Autónoma de Occidente y Facultad de Salud, \\ Universidad del Valle. Cali. \\ ${ }^{2}$ Investigadora asociada a LABIOMOL. Estudiante de Maestría, GeorgiaTech University, USA \\ ${ }^{3}$ Profesor titular Departamento de Ciencias Fisiológicas. Escuela de Ciencias Básicas. Facultad de Salud. \\ Universidad del Valle, Cali. \\ ${ }^{4}$ Profesor Titular y Director Científico del Laboratorio de Biología Molecular y Patogénesis, Departamento \\ de Ciencias Fisiológicas. Escuela de Ciencias Básicas. Facultad de Salud. Universidad del Valle, Cali.
}

\begin{abstract}
Resumen
Uno de los retos más importantes de este siglo en la neurología genómica es construir mapas de expresión espacial de genes a lo largo de las distintas estructuras cerebrales con el fin de correlacionarlos con ciertas neuropatologías. Se analizaron los perfiles de transcripción de ocho genes HAS21 localizados en la región crítica del síndrome de Down en diferentes estructuras del cerebro humano normal. Se tomaron como referencia los valores de expresión de ocho genes HAS21/DSCR provenientes de experimentos de micromatrices de $\mathrm{ADN}$ de cerebros humanos normales y cuyos valores están disponibles en la base de datos del proyecto cerebro humano del Atlas del Cerebro del Allen Institute for Brain Sciences en Seattle, Washington (http://www.brain-map.org). Se determinó una expresión diferencial de estos genes HAS21/DSCR a lo largo de las estructuras localizadas en el lóbulo frontal, el lóbulo límbico y en los núcleos centrales. En el putamen, el núcleo caudado, el giro parahipocampal y en las áreas centrales se registraron los mayores niveles de transcripción global; estas áreas del cerebro parecen estar asociadas con diversos procesos de aprendizaje y de memoria. Se correlacionó la transcripción diferencial de genes DSCR con la localización cerebral y su potencial papel funcional.
\end{abstract}

Palabras claves: Análisis de micromatrices, perfilación de la expresión génica, biología computacional, cerebro, síndrome de Down.

\section{IN SILICO SYSTEMIC ANALYSIS OF THE DIFFERENTIAL EXPRESSION OF GENES LOCALIZED IN THE DOWN SYNDROME CRITICAL REGION (DSCR) IN NORMAL HUMAN BRAIN}

\begin{abstract}
One of the most important challenges of the 21st Century Neurology is to build gene expression profiles along the different structures of human brain trying to correlate them with some neuropathologies. The expression profiles of eight HAS21 genes located on the Down syndrome critical region

* Correspondencia: Dr. Felipe García Vallejo. Director Científico del Laboratorio de Biología Molecular y Patogénesis. Profesor Titular Departamento de Ciencias Fisiológicas. Escuela de Ciencias Básicas. Facultad de Salud. Universidad del Valle. Sede de San Fernando. Calle 4B\# 36-00.Cali. Colombia. Teléfono: +2-5185601. Fax: +2-5185617. E-mail: labiomol@gmail.com.
\end{abstract}


in different structures of the normal human brain was analyzed. From DNA microarray experiments of normal human brains which are available in the free access human brain database of the Brain Atlas project of the Allen Institute for Brain Sciences in Seattle, Washington (http://www.brainmap.org) expression levels data of eight HSA21/DSCR genes along different structures of normal human brain were statistically analyzed. A differential expression of these genes HSA21/DSCR in some anatomic structures located in the frontal lobe, limbic lobe and cerebral central nuclei was registered. Putamen, caudate nucleus, parahipocampal gyro and central areas, showed high levels of transcription for those HSA21/DSCR genes included in the study; these areas of the brain appear to be associated with some processes of learning and memory. This study allowed us to correlate the differential transcription of DSCR genes, their structural localization and functional role in brain function.

Key words: DNA microarray analysis, gene expression profiling, computational biology, brain, Down Syndrome.

\title{
ANÁLISE SISTÊMICA IN SILICO DA EXPRESSÃO DIFERENCIAL DE GENES LOCALIZADOS NA REGIÃO CRÍTICA DA SÍNDROME DE DOWN (DSCR) NO CÉREBRO HUMANO
}

\begin{abstract}
Resumo
Um dos maiores desafio deste século na neurologia genômica é construir mapas de expressão espacial de genes ao longo das diferentes estruturas cerebrais com o fim de correlacioná-los com certas neuropatologias. Foram analisados os perfis de transcrição de oito genes HAS21 localizados na região crítica da síndrome de Down em diferentes estruturas do cérebro humano normal. Foram usados como referência os valores de expressão de oito genes HAS21/DSCR provenientes de experimentos de micromatrizes de ADN de cérebros humanos normais e cujos valores estão disponíveis no bando de dados do projeto cérebro humano do Atlas do Cérebro do Allen Institute for Brain Sciences em Seattle, Washington (http://www.brain-map.org). Determinou-se uma expressão diferencial destes genes HAS21/DSCR ao longo das estruturas localizadas no lóbulo frontal, o lóbulo límbico e nos núcleos centrais. No putâmen, o núcleo caudado, o giro parahipocampal e nas áreas centrais foram registrados os maiores níveis de transcrição global; estas áreas do cérebro parecem estar associadas com diversos processos de aprendizagem e de memória. Correlacionou-se a transcrição diferencial de genes DSCR com a localização cerebral e seu potencial papel funcional.
\end{abstract}

Palavras chave: Análise de micromatrizes, perfil da expressão gênica, biologia computacional, cérebro, síndrome de Down.

\section{Introducción}

El cerebro de los mamíferos y en especial el humano, es el órgano más complejo, pues está compuesto por cientos de subtipos diferentes de neuronas que se entremezclan con varios tipos de células gliales y de células no neuronales, en el que todas ellas difieren en la expresión de genes y en la respuesta a estímulos particulares (1,2). Además, el cerebro es "plástico", en el sentido que muestra una gran capacidad de cambio a lo largo de la vida (3).
Se ha determinado que la complejidad de la transcripción de ARNm excede a la de otros tejidos (4), lo cual se pone en evidencia en la sensibilidad de los análisis de micromatrices de ADN que muestran una sobreexpresión de genes en el cerebelo en comparación con la de transcritos neocorticales $(5,6)$. Así pues, los resultados de los análisis de expresión global de genes, son difíciles de interpretar sin la localización, por hibridación in situ, de transcritos individuales a nivel celular $(7,8)$. A este hecho se le suman los cambios funcionales y clínicos que se producen en la 
expresión de genes individuales en el cerebro adulto y los efectos de dilución que se ponen de manifiesto debido a su elevada complejidad tisular $(9,10)$.

Una forma de enfocar esta problemática, es el uso de herramientas computacionales, que permitan extraer información de niveles de expresión de genes a lo largo de las distintas estructuras cerebrales, a partir de bases de datos que contienen información integrada sobre la expresión de miles de genes humanos que se han obtenido del tratamiento experimental y computacional de experimentos de micromatrices de $\mathrm{ADN}$ de cerebros humanos post-mórten. A pesar de que existen varias de estas bases de datos transcriptómicos, tal vez la más completa es la del cerebro humano consignada en Instituto Allen para la Ciencia del Cerebro y que está disponible de forma gratuita para su utilización (http://www.alleninstitute.org). En ésta se consignan los datos de expresión de genes a partir de ARNm obtenido de preparaciones histológicas de diferentes porciones de cerebro humano cuyo tamaño es de aproximadamente $700 \mu \mathrm{m}$ catalogadas por estructura. La información se ha obtenido de experimentos de hibridación en micromatrices diseñadas que incluyen más de 62.000 sondas entre las que al menos dos diferentes están disponibles para el 93\% de los 21.245 genes referenciados con códigos Entrez Gene.

El primer resultado concreto del Proyecto Genoma Humano, fue el haber secuenciado completamentelos 33,5 Mb del brazo q del cromosoma 21 (11). Este resultado abrió las puertas para poder enfocar de manera genómica ciertas neuropatologías incluyendo el síndrome de Down (SD) y la enfermedad de Alzheimer (EA) asociada. Actualmente se estima que en el cromosoma 21 se localizan unos 400 genes de los cuales se han asignado aproximadamente 160 proteínas y cinco microARNs (12). En el extremo distal del brazo largo del cromosoma 21 (21q22) se identificó una región común de 4,3 a 5 Mb referida como "Región Crítica del Síndrome de Down" (DSCR) que contiene algunos de los genes candidatos que podrían explicar las patologías asociadas con el SD e indirectamente con la EA (13-14) (figura 1A). Recientemente en un análisis in silico, utilizando la información contenida en varias bases de datos genómicos, se demostró que la frecuencia de islas $\mathrm{CpG}$ y de genes referenciados incrementó en los últimos 1,2 Mb de la región distal de la DSCR, en contraste con su distribución pericentromérica. En esta región, la mayor tasa de recom- binación calculada para mujeres, se registró en las bandas 21q22.13 y 21q22.3, donde los genes DSCR 6 y 9 presentaron un elevado grado de metilación en islas $\mathrm{CpG}$ (tanto en fibroblastos normales como en trisómicos). Además, en el gen DSCR2 se observó un alto grado de descondensación cromatínica, asociada con demetilación de diferentes residuos de lisina de la histona H3. La existencia de un ambiente genómico caracterizado por tener elevadas tasas de recombinación y de metilación de genes DSCR 6 y 9, sugirió que esta región desempeña un papel importante no solo en la no disyunción asociada con el $\mathrm{SD}$, sino en las complejas interacciones genómicas, epigenéticas y ambientales que actuarían en la patogénesis del SD (15). A nivel funcional, se ha observado que algunos genes localizados en la DSCR, no se sobreexpresan en el cerebro fetal trisómico, indicando que el fenotipo $\mathrm{SD}$ no se puede explicar simplemente por el efecto en el desbalance de la dosis génica. Existen otros factores epigenéticos y ambientales además de eventos estocásticos que desregulan el transcriptoma trisómico, generando una serie de alteraciones metabólicas. En la tabla 1 se describen las principales características de los ocho genes DSCR que se incluyeron en este trabajo.

En este trabajo, se construyó un modelo in silico de la expresión en 14 subestructuras específicas del ganglio basal y 19 del lóbulo límbico en el cerebro humano normal, de ocho genes localizados en la región crítica del síndrome de Down, a partir de datos de expresión de genes cerebrales provenientes de experimentos de micromatrices de ADN que están disponibles en la base de datos de acceso libre del proyecto cerebro humano del Atlas del Cerebro del Allen Institute for Brain Sciences en Seattle, Washington (http:// www.brain-map.org). Además, se construyó una red de expresión e interacción de estos ocho genes con otros cuya expresión se ha documentado en experimentos previos con micromatrices de ADN. Los resultados permitieron tener un modelo sistémico de expresión, el cual puede ser modificado bioinformáticamente para extrapolarlo a lo que ocurre en otras patologías cerebrales, brindando una herramienta poderosa para su entendimiento.

\section{Metodología}

En el trabajo se presentan los niveles de expresión génica calculados a partir de los valores z score de ocho genes DSCR en distintas subestructuras de los núcleos 
Tabla 1. Descripción de las principales características de ocho genes localizados en la región DSCR incluidos en este trabajo.

\begin{tabular}{|c|c|c|c|c|c|}
\hline Código NCBI & Símbolo & Nombre & Locus & $\begin{array}{c}\text { Proceso } \\
\text { molecular* }\end{array}$ & $\begin{array}{l}\text { Componente } \\
\text { celular** }\end{array}$ \\
\hline 1827 & DSCR1/RCAN1 & $\begin{array}{l}\text { Regulador de Calcineu- } \\
\text { rina } 1\end{array}$ & $21 \mathrm{q} 22.1-\mathrm{q} 22.2$ & $\begin{array}{l}\text { Transcripción depen- } \\
\text { diente de ADN }\end{array}$ & Núcleo \\
\hline 418520 & DSCR2/PSMG1 & $\begin{array}{l}\text { Chaperona de ensamblaje } \\
\text { de proteasoma }\end{array}$ & $21 \mathrm{q} 22.3$ & $\begin{array}{l}\text { Ensamblaje del pro- } \\
\text { teasoma }\end{array}$ & $\begin{array}{l}\text { Reticulo } \\
\text { Endoplasmático }\end{array}$ \\
\hline 10311 & DSCR3 & $\begin{array}{l}\text { Gen } 3 \text { de la región critica } \\
\text { del síndrome de Down }\end{array}$ & $21 \mathrm{q} 22.2$ & Transpote vacuolar & $\begin{array}{l}\text { Retículo } \\
\text { Endoplasmático }\end{array}$ \\
\hline 10281 & DSCR4 & $\begin{array}{l}\text { Gen } 4 \text { de la región critica } \\
\text { del síndrome de Down }\end{array}$ & $21 \mathrm{q} 22.2$ & $\begin{array}{l}\text { Varios procesos invo- } \\
\text { lucrados en retardo } \\
\text { mental }\end{array}$ & ND \\
\hline 51227 & DSCR5/PIGP & $\begin{array}{l}\text { Anclaje de fosfatidilglica- } \\
\text { no de clase P }\end{array}$ & $21 \mathrm{q} 22.2$ & $\begin{array}{l}\text { Preensamblaje de GPI } \\
\text { en membranas de RE }\end{array}$ & $\begin{array}{l}\text { Integral de } \\
\text { membrana }\end{array}$ \\
\hline 53820 & DSCR6 & $\begin{array}{l}\text { Gen } 6 \text { de la región crítica } \\
\text { del síndrome de Down }\end{array}$ & $21 \mathrm{q} 22.2$ & ND & ND \\
\hline 84677 & DSCR8 & $\begin{array}{l}\text { Gen } 8 \text { de la región crítica } \\
\text { del síndrome de Down }\end{array}$ & $21 \mathrm{q} 22.2$ & $\begin{array}{l}\text { Oncogénesisen vários } \\
\text { tipos de tumores }\end{array}$ & ND \\
\hline 259234 & DSCR10 & $\begin{array}{l}\text { Gen } 10 \text { de la región crítica } \\
\text { del síndrome de Down }\end{array}$ & $21 \mathrm{q} 22.13$ & ND & ND \\
\hline
\end{tabular}

(*) Tomado de la página del correspondiente gen de la base de datos Genes and mapped phenotypes. Proceso Molecular, del National Institute for Biotechnology Information (NCBI).

${ }^{(* *)}$ Tomado de la página del correspondiente gen de la base de datos Genes and mapped phenotypes. Componentedel National Institute for Biotechnology Information (NCBI). (ND). No determinado

cerebrales y el lóbulo límbico. Estos se obtuvieron del visor gráfico de la base de datos del cerebro humano del Instituto Allen para las Ciencias del Cerebro. Los distintos procedimientos empleados para la obtención de los datos empleados en este estudio, se consignan de manera extensa en el informe técnico del "Instituto Allen para las Ciencias del Cerebro" disponible en la dirección electrónica (http://human.brainmap.org/ content/WholeBrainMicroarray).

Los valores de z score se calcularon sustrayendo la intensidad promedio total de todos los genes localizados en la micromatriz de la intensidad de cada gen individual dentro de un solo experimento y dividiendo el resultado por la desviación estándar (DS) de la medida de todas las intensidades de acuerdo con la siguiente fórmula: z score $=$ (intensidad $\mathrm{G}-$ intensidad promedio de $\mathrm{G} 1 \ldots$ $\mathrm{Gn}) / \mathrm{DSG} 1 . . . \mathrm{G}$; en donde $\mathrm{G}$ es un gen dentro de la micromatriz y $\mathrm{G} 1$... Gn representa la medida agregada de todos los genes de la micromatriz (16).

\section{Minería de datos}

A partir de la base de datos de micromatrices de ADN del Allen Brain Atlas (http://www.brain-map.org) obtenidos a partir de ADNc de cerebros humanos adultos normales, se seleccionaron diferentes experimentos en los que se identificó la expresión de los genes HSA21/DSCR1 (RCNA1), DSCR2 (PSMG1), DSCR3, DSCR4, DSCR5 (PIGP), DSCR6, DSCR8 y DSCR10 localizados en la región critica del SD (figura 1B). De acuerdo con lo descrito anteriormente, los experimentos seleccionados provenían de ensayos con plataformas de Agilent Human CNV, (la información completa se encuentra en enlace "Documentation" de la página electrónica del Instituto, (http://human. brainmap.org/content/WholeBrainMicroarray).

En todos los casos se obtuvo la información de cada gen de los experimentos disponibles que utilizaban distintas sondas. Se registraron tanto los valores de niveles de expresión como los normalizados (z-score) a lo largo de las distintas subestructuras del Lóbulo Límbico y los Núcleos Centrales (figura 1B). Estos valores fueron consignados en hojas electrónicas en formato Excel para su posterior análisis. Para cada una de las subestructuras incluidas en el estudio, se tomaron tres valores en tres puntos diferentes de cada una de ellas y se consideró como dato final el promedio del z-score que tenía valores normalizados en rangos de $-3 \mathrm{a}+3$. 
(A)

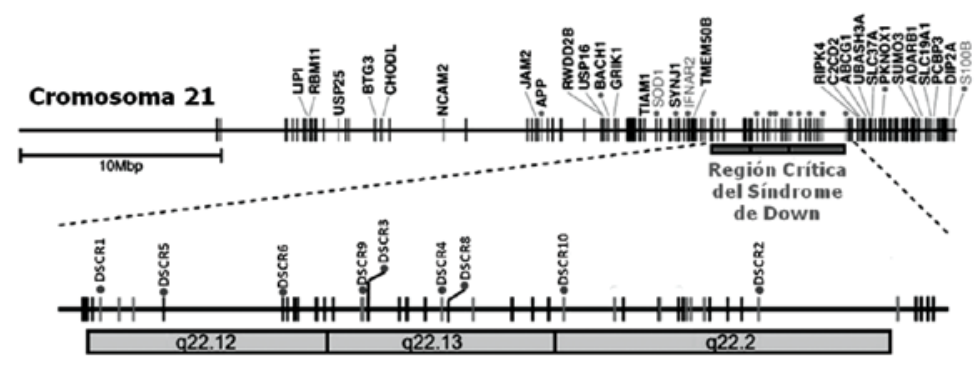

(B)

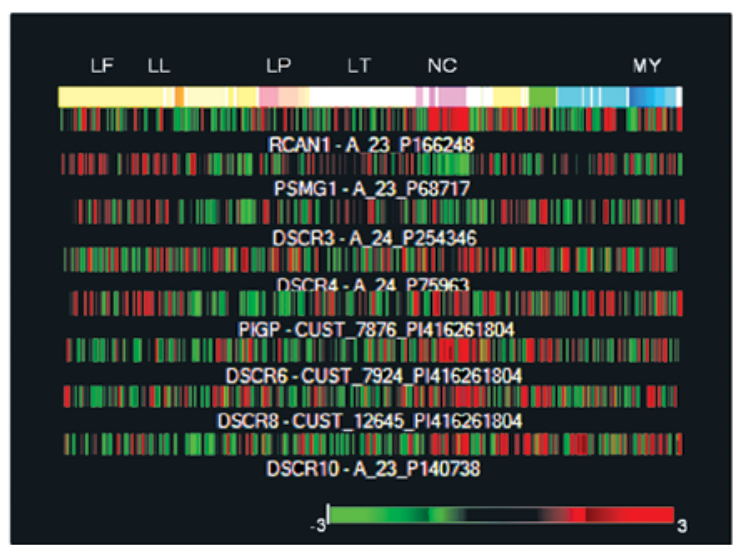

Figura 1. (A). Localización de genes DSCR de la Región Crítica del Síndrome de Down entre las bandas q22.12 y q22.2 del cromosoma 21 humano. Se muestra la distribución de nueve genes DSCR que están implicados en las patologías asociadas con el síndrome de Down. (B). Patrones de hibridación de ADNc de diferentes estructuras del cerebro humano en micromatrices de ADN que incluyen 19.000 genes humanos. Para cada uno de los genes estudiados se tomaron perfiles de expresión usando distintas sondas HAS21/DSCR. (DSCR). Región Crítica del Síndrome de Down. (RCAN1), DSCR1. (PSMG1), DSCR2. (PIGP), DSCR5. (LF). Lóbulo Frontal. (LP). Lóbulo Parietal. (LT). Lóbulo Temporal. (LL). Lóbulo Límbico. (NC). Núcleos Cerebrales y (MY). Mielencéfalo. (Fuente Allen Brain Atlas. http://www.brain-map.org). Las franjas de color rojo corresponden a estructuras cerebrales donde se registra una sobreexpresión del correspondiente gen; las zonas verdes corresponden a estructuras cerebrales donde se registra una subexpresión del correspondiente gen.

\section{Construcción de redes de interacción de proteínas DSCR}

Para construir una red de interacción de las proteínas codificadas por los distintos genes DSCR incluidos en este trabajo con otras expresadas en la plataforma GSE5281 RNA de cerebro total (número de acceso: GN233) (17), se utilizó como herramienta la plataforma bioinformática de la base de datos GeneMania del Donnelly Centre for Cellular and Molecular Structure de la Universidad de Toronto en Canadá. A partir de esta información se construyó una red de interacción de seis proteínas DSCR con otras 40 proteínas humanas consignadas en las diferentes bases de datos, algunas de ellas expresadas en el cerebro humano normal.

\section{Análisis estadísticos}

Los análisis estadísticos se llevaron a cabo empleando los programas Statgraphics Centurion XVI (http:// www.statgraphics.com) y Systat 13 (http://www.systat.com). Las diferencias entre los datos de promedios de los distintos experimentos se calcularon mediante un análisis de comparaciones múltiples estimando su significancia con la prueba de Mann y Whitney para múltiples comparaciones. Las diferencias de niveles de expresión por gen por área anatómica se modelaron mediante el Scatter Plot usando como medida de comparación los valores de correlaciones parciales de Pearson con una significancia del 95\% $(p<0,05)$. Para jerarquizar la expresión en cada uno de los genes en las distintas subestructuras cerebrales, se realizó un análisis de componentes principales 


\section{Análisis Sistémico In Silico de la Expresión Diferencial de Genes Localizados en la Región CRítica DEL SíndRome De Down (DSCR) en el CEREBRo HuMANo}

(ACP) reduciendo el espacio $\mathrm{R}$ de ocho variables colineales a tres componentes principales $(\mathrm{R} 8>\mathrm{R} 3)$.

Para los análisis estadísticos se tomaron tanto los valores de promedios de $\mathrm{z}$-score como aquellos de medianas de experimentos con tres tipos de sondas para cada uno de los genes DSCR incluidos en el estudio. Se excluyeron del estudio aquellos valores en los que no se determinaron diferencias estadísticas significantes; además aquellos valores no repetibles estadísticamente, no fueron incluidos en el presente análisis.

\section{Resultados}

\section{Transcripción global de genes DSCR en el cerebro}

De la inspección visual de los patrones de hibridación de micromatrices de ADN con las diferentes sondas analizadas (figura 1B), se observó una expresión diferencial de los ocho genes DSCR a lo largo de las distintas estructuras cerebrales. Sin embargo, un análisis cuantitativo de la transcripción global de estos ocho genes DSCR a lo largo de 19 subestructuras de los núcleos centrales y de 14 del lóbulo límbico, reveló que en los núcleos centrales, los valores de z-score promedio más altos se registraron en el putamen izquierdo y derecho y en el globo pálido izquierdo y derecho (figura 2). En el lóbulo límbico los valores de expresión más elevados se observaron en el giro parahipocampal y en el área central CA4 (figura 2); mientras que los niveles de expresión más bajos se detectaron en el Tálamo (T), el Tegumento CerebroMedial (TCM) y el Cerebelo (Cb).

Perfiles de transcripción de cada gen en los núcleos centrales y el lóbulo límbico

Los valores más altos de z-score se registraron en el putamen para los genes DSCR1, 6 y 10 junto con el núcleo caudado para los genes DSCR 4, 5, 8 y 10 (figuras 3 a y b). Por otra parte, en el globo pálido y el claustro, los niveles de expresión de cada uno de los genes DSCR fueron variables aunque en general más bajos que en las dos zonas anteriores (figuras 3 c y d). El área central izquierda registró los mayores valores de $z$-score en los genes DSCR1, 2, 3, 4, 5, 6 y 8 junto con el giro parahipocampal en donde la expresión más alta fue para los genes DSCR 4, 5, 8 y 10 (figura 4 a y c). En el subiculum, el área central derecha y el giro dentado la expresión de cada uno de estos genes fue variable, aunque en general más baja que en las dos anteriores (figuras $4 \mathrm{~b}, \mathrm{~d}$ y e).

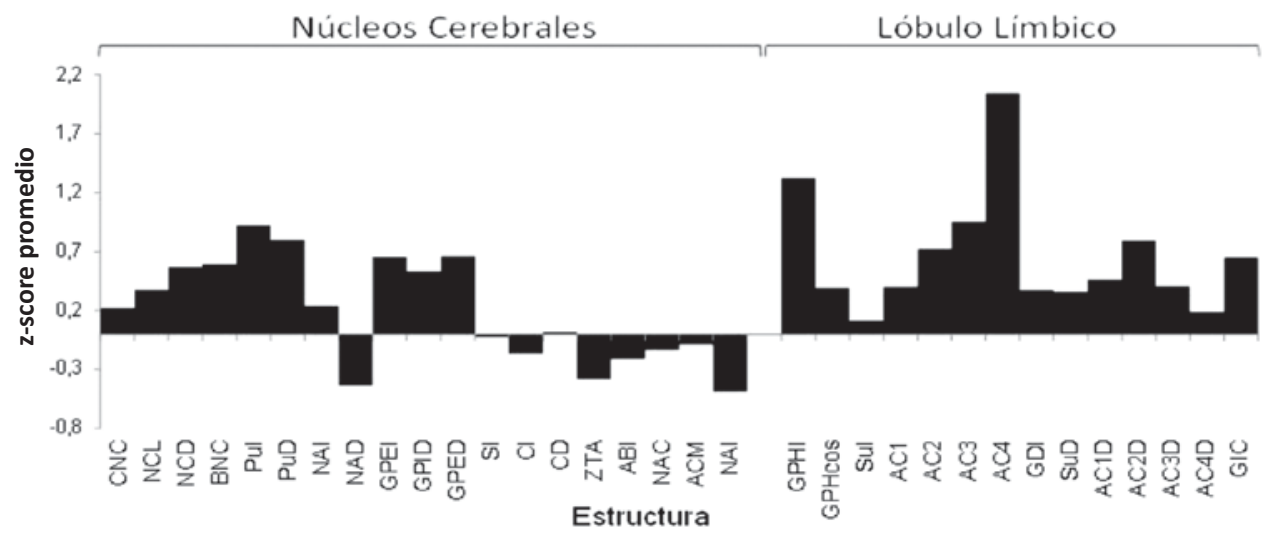

Figura 2. Perfiles de expresión génica global de ocho genes HAS21/DSCR a lo largo de las diferentes estructuras de los núcleos cerebrales y del lóbulo límbico. Se grafican los valores de z-score promedios de los ocho genes DSCR incluidos a lo largo de distintas estructuras del lóbulo límbico de la corteza y de los núcleos cerebrales; éstos valores fueron obtenidos de experimentos hibridación con micromatrices de ADN de ADNc de cerebro humano consignadas en la base de datos de uso libre del Cerebro Humano del Instituto Allen para el estudio del cerebro. (CNC) Cabeza del Núcleo Caudado. (NCI) Núcleo Caudado Izquierdo. (NCD) Núcleo Caudado Derecho. (BNC) Base del Núcleo Caudado. (PuI) Putamen Izquierdo. (PuD) Putamen Derecho. (NAI) Núcleo Acumulado Izquierdo. (NAD) Núcleo Acumulado Derecho. (GPEI) Globo Pálido Externo Izquierdo. (GPID) Globo Pálido Interno Derecho. (GPED) Globo Pálido Externo Derecho. (CBA) Cerebro Anterior Basal (SID) Sustancia Innominada Derecha. (CI) Claustro Izquierdo. (CD) Claustro Derecho. (ZTA) Zona de Transición de la Amígdala. (ABI) Amígdala Basolateral Izquierda. (NCA) Núcleo Central de la Amígdala. (ACM) Amígdala Corto Medial. (NIA) Núcleo Izquierdo de la Amígdala. (GPHI) Giro Parahipocampal Izquierdo. (GPHCcos) Giro Parahipocampal cos. (SuI) Subiculum Izquierdo. (AC1I) Área Central 1 Izquierda. (AC2I) Área Central 2 Izquierda. (AC3I) Área Central 3 Izquierda. (AC4I) Área Central 4 Izquierda. (GDI) Giro Dentado Izquierdo. (SuD) Subiculum Derecho. (AC1D) Área Central 1 Derecha. (AC2D) Área 2 Central Derecha. (AC3D) Área 3 Central Derecha. (AC4D) Área 4 Central Derecha. (GIC) Giro Insular Corto. 
(A)

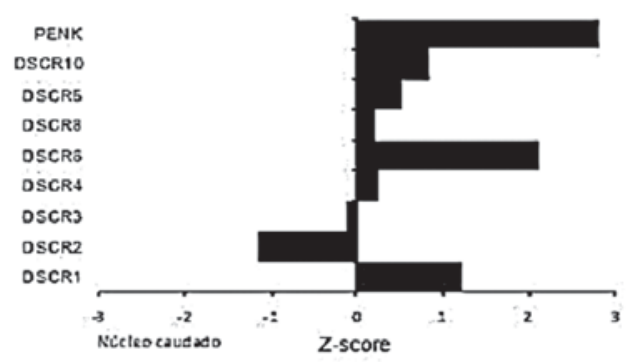

(C)

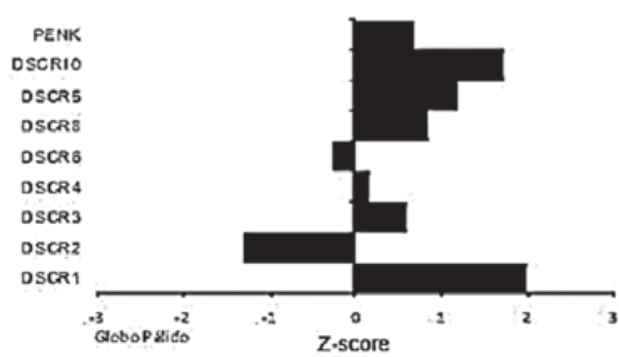

(B)

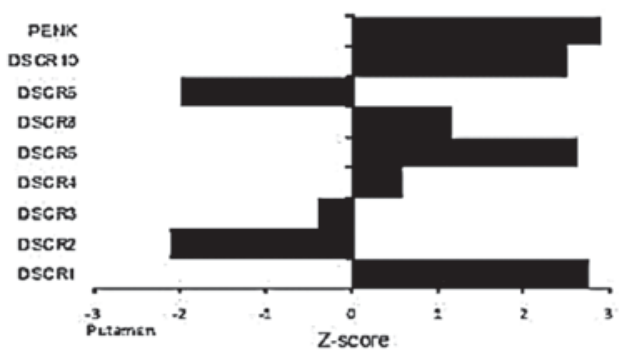

(D)

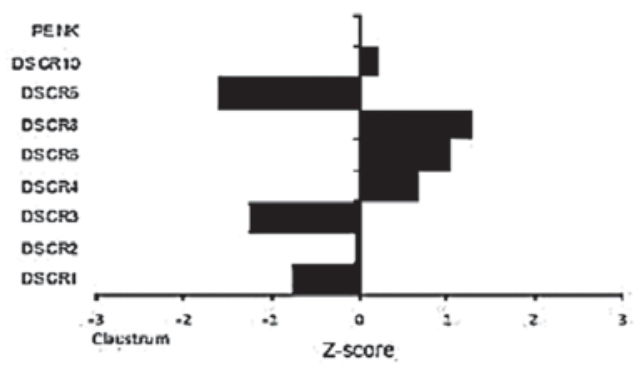

Figura 3. Perfiles de expresión diferencial de cada uno de los ocho genes DSCR en distintas subestructuras de los núcleos cerebrales. (A). Núcleo caudado. (B). Putamen. (C). Globo pálido. (D). Claustro. Se empleó como gen reportero aquel que codifica por la pro-encefalina (PENK) (Gene ID: 5179) (http://www.ncbi.nlm.nih.gov/gene/), cuya expresión a lo largo de las distintas estructuras cerebrales ha sido documentada previamente.

(A)

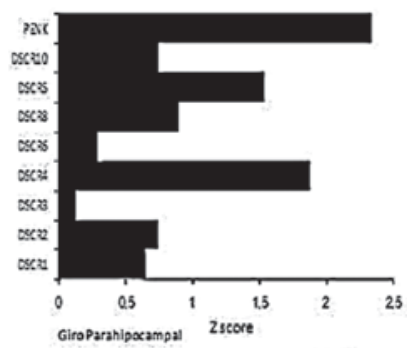

(D)

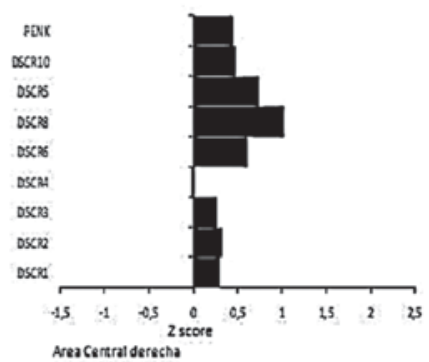

(B)

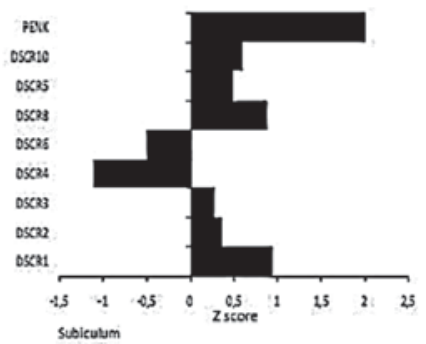

(E)
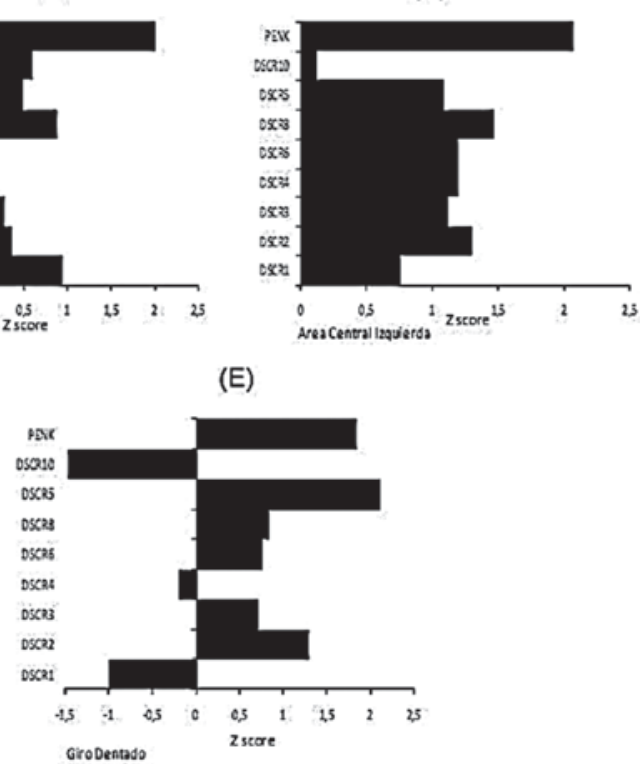

Figura 4. Perfiles de expresión de cada uno de los ocho genes DSCR en distintas subestructuras del lóbulo límbico. (A) Giro parahipocampal. (B). Subiculum. (C) Área central izquierda. (D). Área central derecha. (E). Giro dentado. Claustro. Se empleó como gen reportero el que codifica por la pro-encefalina (PENK) (Gene ID: 5179) (http://www.ncbi.nlm.nih.gov/gene/), cuya expresión a lo largo de las distintas estructuras cerebrales ha sido documentada previamente. 


\section{Análisis Sistémico In Silico de la Expresión Diferencial de Genes Localizados en la Región CRítica Del SíndRome de Down (DSCR) en el CEREBRo HuMANo}

El análisis de componentes principales permitió reducir a tres componentes los valores de z-score de los ocho genes DSCR en las dos estructuras cerebrales previamente descritas. Para los núcleos cerebrales las tres componentes principales representaron el $78,9 \%$ de la varianza total, mientras que para el lóbulo límbico el 65,9\%. Se observó que la distribución de los ocho genes DSCR fue diferencial en las dos estructuras cerebrales (tabla 2). El componente 1 fue el más complejo de los tres e incluyó, para los núcleos cerebrales, a los genes DSCR 1, 3 y 10, en contraste con la del lóbulo límbico que estuvo conformado por los DSCR 1, 4, 8 y 10. Un análisis comparativo de los gráficos Biplot, permitió establecer que para los núcleos cerebrales se detectaron dos asociaciones de genes DSCR cuyos resultantes fueron positivas, DSCR 6-10 y DSCR 8-4; mientras que en el lóbulo límbico solamente una DSCR 6-2.

\section{Interacciones de proteínas codificadas por los genes DSCR}

En general se pudo establecer una asociación mediante interacción de 6 proteínas DSCR con 40 humanas, algunas de ellas se expresaban en el cerebro humano normal. De acuerdo con lo que se muestra en la figura 5 , se diferenciaron tres nodos principales, dentro de los cuales un número variable de proteínas humanas interactuaba directamente con algunas de las seis proteínas DSCR.

El nodo I incluyó 22 proteínas que interactuaban con la reguladora de la calcineurina o DSCR1 (RCNA1), de las cuales 5 de ellas directamente (figura 5). DSCR1 interactuó directamente con PPP3CA que es la subunidad catalítica de la Proteína fosfatasa 3 alfa ubicada en el locus 4q24, la cual es una Treonina fosfatasa, ésta participa en procesos de desfoforilación de proteínas; y con PPP3CB, la subunidad catalítica de la Proteína fosfatasa 3 beta. De acuerdo con el Brain Atlas de Affymetrix, ambas proteínas se expresan en cerebro adulto; sin embargo PPP3CA lo hace especialmente en el núcleo caudado y el globo pálido.

El nodo II incluyó la interacción de DSCR3 directamente con la Prefoldina 2 (PFDN2) que participa activamente de los procesos de plegamiento de proteínas haciendo parte del complejo de pre-plegamiento citoplasmático. Indirectamente con DSCR8 y MAP3K3, esta última una Proteína Cinasa-Cinasa-Cinasa activada por mitógenos que es componente de la cascada MAPKKK. Además, con la proteína básica rica en triptófano -WRB- expresada en muchos tejidos embrionarios y adultos; se propone que esta proteína representaría un papel importante en la cardiopatía congénita que se presenta muy frecuentemente en pacientes con SD (figura 5).

El nodo III estuvo conformado por ocho proteínas que interactuaban directamente entre sí, en el que PIGP (DSCR5) conformó una red local con otras enzimas que hacen parte de la biosíntesis del anclaje a membranas del fosfatidilinositolglicano (GPI) entre las que se incluyeron PIGA, PIGH, PIGQ y PIGC. Otra interacción importante se determinó entre el grupo de las dolicil-fosfato/manosiltransferasas, DPM 1, 2 y 3 que controlan la síntesis de Dolicol-Fosfato-Manosa (Dol-P-Man) y son donadoras de residuos manosil al interior de Retículo Endoplasmático (figura 5).

De las veinte principales categorías $\mathrm{GO}$ registradas en la red construida, aquellas que participan en el metabolismo del Glicofosfatidil Inositol y su anclaje en las membranas, junto con los diferentes procesos de biosíntesis de lípidos, fosfolípidos y órganofosfatos fueron las más significantes. Este resultado sugiere que la interacción de los genes DSCR es fundamental en la regulación de estas rutas metabólicas que ocurren en los distintos componentes celulares del cerebro humano. De otra parte los procesos de transducción de señales que involucran señalización por proteína $G$ acoplada a cAMP segundo mensajero, la mediada por nucleótidos cíclicos y vía proteína $G$, que también presentaron valores significantes, sugieren que estas funciones son importantes como parte de los mecanismos de integración de la información que ocurren en el cerebro.

\section{Discusión}

Construimos un modelo in silico de perfiles de transcripción diferencial de ocho genes localizados en la DSCR a lo largo de 19 estructuras de los núcleos cerebrales y de 14 del lóbulo límbico en donde se demostró que la transcripción de estos genes fue diferencial y específica, además de ser dependiente de la estructura cerebral asociada. Así pues, se puede concluir que en el cerebro normal, los ocho genes DSCR analizados, estarían sometidos a una regulación muy precisa de su transcripción, siendo ésta dependiente de la fisiología de cada una de los componentes estructurales del cerebro. Estadísticamente se confirmó la coexpresión de los genes estudiados agrupados en componentes diferentes en las dos estructuras cerebrales analizadas; siendo una 


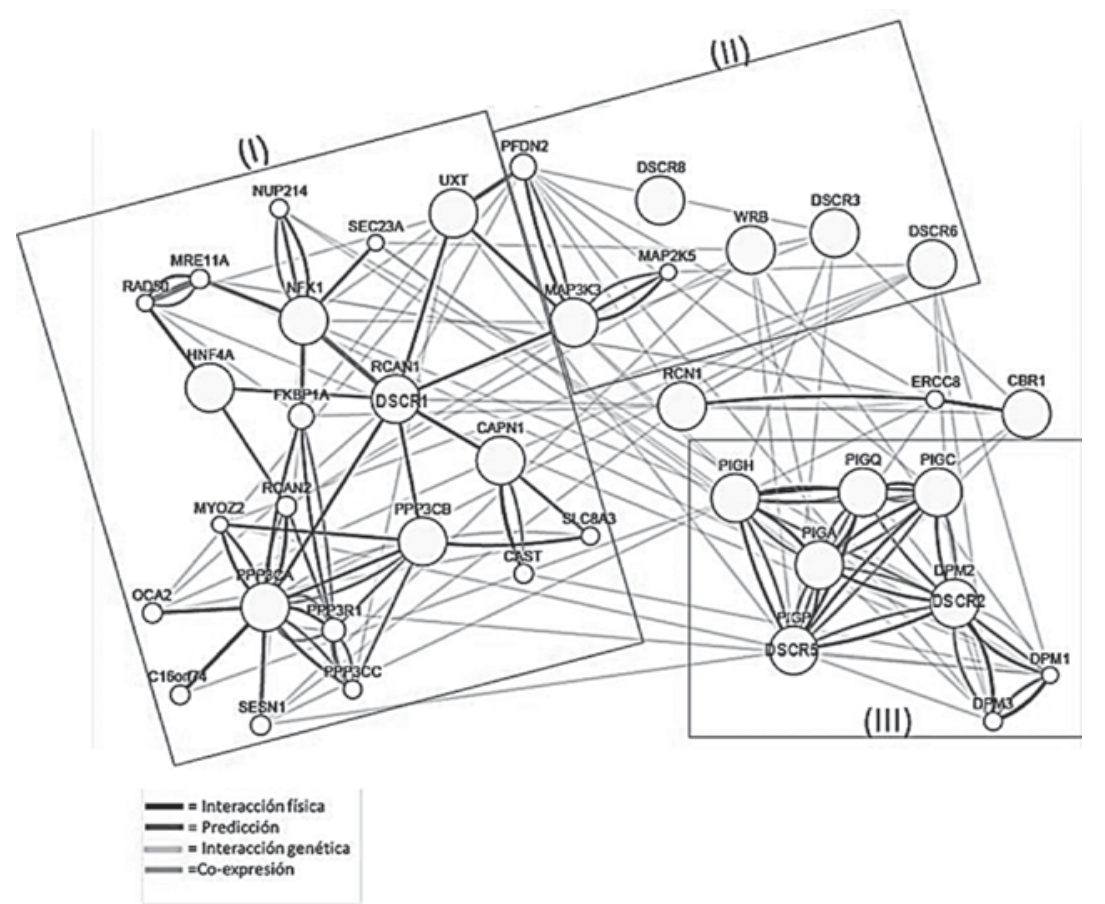

Figura 5. Red de interacción de proteínas asociadas con la expresión de los ocho genes DSCR analizados. Se utilizó el software de la base de datos GeneMania del Donnelly Centre for Cell Biology and Molecular Structures, de la Universidad de Toronto en Canadá (http://www.genenania.org/). Las abreviaturas de cada una de las proteínas incluidas en la red, corresponden a las consignadas en la base de datos de Genes and mapped phenotypes del National Center for Biotechnology Information (NCBI). (http:// www.ncbi.nlm.nih.gov/gene/)

Tabla 2. Coexpresión de los ocho genes de la región DSCR en núcleos cerebrales y el lóbulo límbico y agrupación en tres componentes principales diferentes. Se empleó el gen PENK como gen reportero.

\begin{tabular}{|l|c|c|c|}
\hline \multicolumn{1}{|c|}{ Estructura Cerebral } & Componente 1 & Componente 2 & Componente 3 \\
\hline Núcleos Cerebrales & $\begin{array}{c}\text { DSCR1, DSCR2, DSCR3, } \\
\text { DSCR10, PENK* }\end{array}$ & DSCR8 & DSCR4, DSCR5 \\
\hline Lóbulo Límbico & $\begin{array}{c}\text { DSCR1, DSCR2, DSCR4, } \\
\text { DSCR8, DSCR10 }\end{array}$ & DSCR3, PENK* & DSCR6, DSCR5 \\
\hline
\end{tabular}

(") PENK, gen que codifica para la Pro-encefalina (Código NCBI: 5179), ubicado en el locus 8q23-q24.

evidencia más de la regulación estructura específica de la transcripción de los ocho genes DSCR analizados.

Reportes previos han mostrado una elevada expresión del gen DSCR1。 RCAN1 en corteza, cerebro medio y cerebelo de ratones SD (18) y del gen DSCR5 o PIGP en el cerebro en desarrollo (19). En el presente estudio, se determinó que los niveles de expresión global más elevados se detectaron en el putamen y el núcleo caudado; de otra parte en el lóbulo límbico, las áreas centrales y el giro hipocampal registraron niveles altos de transcripción. Tomados en su con- junto, los resultados sugieren que la transcripción de estos genes en el cerebro humano es coincidente con aquella obtenida para ratones.

Individuos con SD inevitablemente desarrollan, en algún periodo de su vida, enfermedad de Alzheimer (EA); aunque el mecanismo por el cual se desarrolla la neuropatología EA no está bien definido en los pacientes SD (20). Sin embargo, se sugiere que la fosforilación de la Presenilina 1 mediada por Dyrk1A establecería un puente funcional entre el SD y la EA (21); la sobreexpresión de RCAN1 en neuronas 


\section{Análisis Sistémico In Silico de la Expresión Diferencial de Genes Localizados en la Región CRítica Del SíndRome de Down (DSCR) en el CEREBRo HuMANo}

primarias conlleva a la activación de la síntesis de caspasa-9 y caspasa-3 induciendo apoptosis neuronal que complementaría el mecanismo de depósito de las placas amiloideas (22). Además, se ha determinado previamente que la sobreexpresión de PIG-P (DSCR5) puede alterar las modificaciones postraduccionales y el subsecuente anclaje de proteínas de membrana mediados por la glicosilfosfatidilinositol- N-acetil-glucosamini-transferasa(GPI-GnT) (23). PIG-P (DSCR5) se sobreexpresa dos veces en la corteza cerebral en contraste con DSCR6 cuya expresión fue normal (24).

Además, de la concordancia de estos resultados experimentales con los obtenidos a partir de nuestro modelo in silico, se obtuvo una mayor resolución estructural de la transcripción de los genes DSCR, lo que nos permitió construir perfiles transcripcionales que son dependientes de la estructura del cerebro involucrada. Estas evidencias indicarían que el fenotipo de algunas de las enfermedades neurológicas que actualmente aquejan a nuestra especie como el SD y EA entre otras, no puede explicarse simplemente por la expresión alterada de un gen, sino por el contrario, serían el producto de la alteración de las múltiples interacciones génicas que controlan la homeostasis cerebral.

Fue evidente que la expresión de los ocho genes DSCR tuvo su máximo en el putamen, el globo pálido y el núcleo caudado. El Putamen es la porción de los núcleos basales que forma la parte más externa del núcleo lenticular y parece desempeñar un importante papel en el condicionamiento operante (aprendizaje a través de refuerzo). Las cortezas somatosensorial y motora, el núcleo intralaminar del tálamo y la sustancia negra se proyectan al putamen y éste, a su vez, proyecta en áreas motoras y premotoras de la corteza a través del globo pálido y el tálamo (25). Por otra parte, el núcleo caudado es uno de los componentes de los ganglios basales localizados junto al cerebelo, participa en la modulación del movimiento; previamente se ha demostrado que el núcleo caudado está fuertemente involucrado en el aprendizaje y la memoria (26), en particular en materia de tratamiento de retroalimentación (27). El lóbulo límbico, contiene la circunvolución del cuerpo calloso, la circunvolución subcallosa y el giro parahipocampal, y es aparentemente el principal responsable de la vida afectiva, influenciando la formación de memorias, en las que participan el hipotálamo, el hipocampo, la amígdala y cuatro áreas relacionadas. Los resultados obtenidos en este estudio permitieron correlacionar elevados niveles de transcripción de los genes DSCR en estas estructuras con su potencial papel en las funciones asociadas (28).

La interacción entre proteínas que se obtuvo en la red, mostró que varias de ellas se expresan en el cerebro e interactúan directamente con DSCR1, 2, 6 y 8, además de otras, conformando una red compleja de interacción de proteínas expresadas en el cerebro (29). Este hecho nos da un punto de partida para analizar desde la biología integrada de sistemas, alteraciones cerebrales como EA, SD y otras no menos importantes que afectan el funcionamiento normal de las actividades cerebrales (30), además de la comparación funcional entre especies (31). Este primer acercamiento ya nos mostró que en un análisis de baja resolución, esta interacción sería muy compleja.

Aunque el fenotipo de la trisomía 21 es variable y complejo, todos los pacientes con SD tienen deficiencias de aprendizaje que van desde moderadas a severas. Recientes trabajos con el modelo de ratón SD transcromosómico ( $\mathrm{Tc} 1$ ), han permitido examinar en detalle los procesos de aprendizaje que estarían afectados por la trisomía del par 21 (32). Los análisis en el ratón Tc1modelo, mostraron anormalidades en los procesos de aprendizaje de corto plazo, dependientes de la función hipocampal, pero no en los de largo plazo. Los déficits de aprendizaje se correlacionaron con anormalidades en la potenciación de largo plazo (PLP) del giro dentado del hipocampo (33). Más aún, recientes hallazgos han mostrado alteraciones en el número de componentes sinápticas en el hipocampo de ratones transgénicos Ts 65DN (34).

Nuevos y excitantes hallazgos han revelado que en el genoma humano opera una considerable plasticidad, la cual de manera directa o indirecta afecta no solo la expresión de genes localizados en el cromosoma 21 sino de otros ubicados en los otros cromosomas. Este hecho nos lleva a considerar que la gran variabilidad del fenotipo SD sería el resultado de la alteración en el número de copias de elementos genómicos no tradicionales. El estudio del transcriptoma de la trisomía 21 (T21) mediante micromatrices de ADN asociado a medidas de PCR cuantitativo tanto en trisomías completas como en segmentales, ha confirmado que más del $50 \%$ de los genes localizados en el cromosoma 21 , tienen número de copias variable mayor que el fenotipo normal euploide $(35,36)$. 
En un esfuerzo por correlacionar el efecto del desbalance de la dosis de genes HAS21 con la potencial alteración en los perfiles de transcripción asociada a diferentes subestructuras cerebrales de los ocho genes DSCR incluidos en este trabajo, se tomaron como punto de partida los resultados obtenidos por YahyaGraison et al.(37). Mediante mediciones obtenidas de micromatrices de ADN construidas con sondas que representaban 145 genes, $58 \mathrm{ORFs}, 118$ predicciones y 18 transcritos antisentido del cromosoma 21, se calcularon las relaciones de niveles de expresión génica en líneas celulares de pacientes con SD y se compararon con los de personas normales. De acuerdo con los resultados obtenidos, los genes HSA21 analizados se clasificaron en cuatro clases cuyos valores de relaciones de expresión $\mathrm{SD} /$ control eran característicos. En la clase I se incluyeron aquellos cuyos valores de relación de expresión $\mathrm{SD} /$ control, eran mayores a 1,5 y que por lo tanto serían genes con tres copias. En nuestro estudio, el gen PIGP (DSCR5) se incluyó en esta clase y por lo tanto se infiere que sufre el efecto de desbalance de la dosis. La clase II está conformada por genes cuyas relaciones DS/control eran significantemente diferentes de 1 y de 1,5; en este grupo el gene DYRK1A, está bajo el efecto de dosis génica. La clase III, la conforman un grupo de genes cuyas relaciones de expresión DS/control, son $<1.4$; estos genes clase III están compensados en el paciente con SD e incluyeron a DSCR1, 2, 3, 6, 8 y 10 de nuestros análisis. Finalmente, la clase IV está representada por genes cuya relación de expresión es mayor que 1 pero menor que 1,5 y tienen una alta variabilidad entre los pacientes y los normales; de nuestro estudio, el gen DSCR4 se incluyó dentro de esta clase.

Puesto que el único gen clase I incluido en este trabajo que sufre el desbalance de dosis y se presenta en tres copias fue el DSCR5 (PIGP), es posible interpretar que el mayor efecto sobre la alteración de los perfiles de transcripción de diferentes estructuras cerebrales en pacientes con $\mathrm{SD}$, se deberá a este gen. Así pues, en los núcleos caudados, el globo pálido, el giro parahipocampal, el giro dentado y el área central 4, los perfiles de transcripción sufrirían el efecto del desbalance de la dosis de PIGP (DSCR5). En consecuencia se puede inferir una alteración de la función que desempeñan estas estructuras, principalmente en el aprendizaje, y la memoria (26), en particular en materia de tratamiento de retroalimentación, la vida afectiva y la formación de memorias cuya disfunción es característica del síndrome de Down.
Con base en los resultados y la correlación anatómica de la expresión diferencial demostrada en este estudio, es posible postular como hipótesis de trabajo que la potencial alteración de los perfiles transcripcionales, además del desbalance de la dosis de los genes DSCR en las neuronas del ganglio basal y del lóbulo límbico, podrían ser factores importantes en la desregulación de sus funciones asociadas, conllevando a una disfunción del aprendizaje y la memoria, rasgos éstos que se observan en grados variables en los fenotipos SD y EA.

Los recientes resultados, referenciados en los párrafos anteriores, sustentan la hipótesis de que existe una elevada variación en los fenotipos de los pacientes $\mathrm{SD}$, atribuible no tanto a genes específicos sino más bien a la sobreexpresión o subexpresión de dominios cromosómicos completos. En este sentido, el SD debería enfocarse como un prototipo de desorden genómico, además de convertirse en un excelente modelo para la implementación de una neurociencia sistémica (38-40).

El modelo desarrollado en nuestro trabajo, sirve de punto de partida para efectuar un análisis sistémico de la alteración de los perfiles de expresión génica de subestructuras del cerebro en otras enfermedades neurológicas cuya patogénesis es compleja e involucra numerosas redes de interacción de expresión de genes. De tal manera que el enfoque bioinformático se convierte en una herramienta poderosa para abordar un grupo creciente de enfermedades crónicas que se han convertido en problemas de salud pública a nivel mundial.

\section{Agradecimientos}

A la Universidad Autónoma de Occidente y la Universidad del Valle por el apoyo financiero y de infraestructura para la ejecución de este estudio.

Conflicto de intereses. Los autores declaran no tener ningún conflicto de intereses con los resultados de este trabajo.

\section{Referencias bibliográficas}

1. Stevens CF. Neuronal diversity: too many cell types for comfort? Curr Biol. 1998; 8(20):R708-10.

2. Oldham MC, Konopka G, Iwamoto K, Langfelder P, Kato T, Horvath S, et al. Functional organization of the transcriptome in human brain. Nat Neurosci. 2008; 11(11):1271-82.

3. Loebrich S, Nedivi E. The function of activity-regulated genes in the nervous systen. Physiol Rev. 2009; 89:1079-103.

4. Sutcliffe JG. mRNA in the mammalian central nervous system. Annu Rev Neurosci. 1988; 11:157-98. 


\section{Análisis Sistémico In Silico de la Expresión Diferencial de Genes Localizados en la Región CRÍtica DEL SíndRome De Down (DSCR) en el Cerebro Humano}

5. Sandberg R, Yasuda R, Pankratz DG, Carter TA, Del Rio JA, Wodicka L, et al. Regional and strain-specific gene expression mapping in the adult mouse brain. Proc Natl Acad Sci USA. 2000; 97:11038-43.

6. Geschwind DH. Mice, microarrays, and the genetic diversity of the brain. Proc Natl Acad Sci USA. 2000; 97:10676-78.

7. Zirlinger M, Kreiman G, Anderson DJ. Amygdala-enriched genes identified by microarray technology are restricted to specific amygdaloid subnuclei. Proc Natl Acad Sci USA. 2001; 98:5270-75

8. Lein ES, Zhao X, Gage FH. Defining a molecular atlas of the hippocampus using ADN microarrays and high-throughput in situ hybridization. J Neurosci. 2004;24:3879-89.

9. McClung CA, Nestler E. Regulation of gene expression and cocaine reward by CREB and Delta Fos B. Nat Neurosci. 2003; 6:1208-15.

10. Lewis NE, Schramm G, Bordbar A, Schellenberger J, Andersen MP, Cheng JK, et al. Large-scale in silico modeling of metabolic interactions between cell types in the human brain. Nature Biotechnol. 2010; 28(12):1279-85.

11. Hattori M, Fujiyama A, Taylor TD, Watanabe H, Yada T, Park HS, et al. Chromosome 21 mapping and sequencing consortium. The ADN sequence of human chromosome 21. Nature. 2000; 405:311-9.

12. Gardiner K, Herault Y, Lott IT, Antonarakis SE, Reeves $\mathrm{RH}$, Dierssen M. Down syndrome: from understanding the neurobiology to therapy. J Neurosci.2010; 30(45):14943-5.

13. Toyoda A, Noguchi H, Taylor TD, Ito T, Pletcher MT, Sakaki $\mathrm{S}$, et al. Comparative genomic sequence analysis of the human chromosome 21 Down Syndrome Critical Region. Genome Res. 2002; 12:1323-32.

14. Eggermann T, Schönherr N, Spengler S, Jäger S, Denecke B, Binder $G$, et al. Identification of a 21q22 duplication in a Silver-Russell syndrome patient further narrows down the Down syndrome critical region.Am J Med Genet. 2010; 152A:356-59.

15. Montoya JC, Soto J, Satizábal JM, Sánchez A, García-Vallejo F. Genomic study of the critical region of chromosome 21 associated to Down syndrome. Colombia Médica. 2011; 42:26-38.

16. Cheadle C, Vawter MP, Freed WJ, Becker KG. Analysis of microarray data using $\mathrm{Z}$ score transformation. J Mol Diagn. 2003; 5:73-81.

17. Liang WS, Reiman EN, Valla J, Dunckley T, Beach TG, Grover $\mathrm{A}$, et al. Alzheimer's disease is associated with reduced expression of energy metabolism genes in posterior cingulate neurons. Proc Natl Acad Sci USA. 2008;105:4441-46.

18. Amano K, Sago H, Uchikawa C, Suzuki T, Kotliarova SE, Nukina $\mathrm{N}$, et al. Dosage-dependent over-expression of genes in the trisomic region of Ts1Cje mouse model for Down syndrome. Hum Mol Genet. 2004; 13:1333-40.

19. Shao M, Liu ZZ, Wang CD, Li HY, Carron C, Zhang HW, et al. Down syndrome critical region protein 5 regulates membrane localization of Wnt receptors, Dishevelled stability and convergent extension in vertebrate enbryos. Development. 2009; 136:2121-31.

20. Head E, Lott IT, Patterson D, Doran E, Haier RJ. Possible compensatory events in adult Down syndrome brain prior to the development of Alzheimer disease neuropathology: targets for nonpharmacological intervention. J Alzheimers Dis. 2007; 11:61-76.

21. Ryu YS, Park SY, Jung MS, Yoon SH, Kwen MY, Lee SY, et al. Dyrk1A-mediated phosphorylation of Presenilin 1: a functional link between Down syndrome and Alzheimer's disease. J Neurochem. 2010;115:574-84.
22. Sun X, Wu Y, Chen B, Zhang Z, Zhou W, Tong Y, et al. Regulator of calcineurin 1 (RCAN1) facilitates neuronal apoptosis through caspase-3 activation. J Biol Chem. 2011; 286:9049-62.

23. Ferrando-Miguel R, Cheon MS, Lubec G. Protein levels of genes encoded on chromosome 21 in fetal Down syndrome brain (Part V): overexpression of phosphatidyl-inositol-glycan class P protein (DSCR5). Amino Acids. 2004; 26:255-61.

24. Shibuya K, Kudoh J, Minoshima S, Kawasaki K, Asakawa S, Shimizu N. Isolation of two novel genes, DSCR5 and DSCR6, from Down syndrome critical region on human chromosome 21q22.2. Biochem Biophys Res Commun2000; 271:693-8.

25. Graybiel AM. The basal ganglia: learning new tricks and loving it. Curr Opin Neurobiol. 2005; 15:638-44.

26. Packard MG, Knowlton BJ. Learning and memory functions of the Basal Ganglia. Annu Rev Neurosci. 2002; 25:563-93.

27. Dierssen M, Herault Y, Estivill X. Aneuploidy: from a physiological mechanism of variance to Down syndrome. Physiol Rev. 2009;89(3):887-920.

28. Osada T, Adachi Y, Kimura HM, Miyashita Y. Towards understanding of the cortical network underlying associative memory. Philos Trans R Soc Lond B Biol Sci. 2008;363:2187-99.

29. Potier MC, Rivals I, Mercier G, Ettwiller L, Moldrich RX, Laffaire J, et al. Transcriptional disruptions in Down syndrome: a case study in the Ts1Cje mouse cerebellum during post-natal development. J Neurochen. 2006; 97 Suppl 1:104-9.

30. Lee S, Lee E, Lee KH, Lee D. Predicting disease phenotypes based on the molecular networks with condition-responsive correlation. Int J Data Min Bioinform.2011; 5:131-42.

31. Miller JA, Horvath S, Geschwind DH. Divergence of human and mouse brain transcriptome highlights Alzheimer disease pathways. Proc Natl Acad Sci USA.2010; 107:12698-703.

32. O'Doherty A, Ruf S, Mulligan C, Hildreth V, Errington ML, Cooke $\mathrm{S}$, et al. An aneuploid mouse strain carrying human chromosome 21 with Down syndrome phenotypes. Science. 2005;309:2033-7.

33. Morice E, Andreae LC, Cooke SF, Vanes L, Fisher EM, Tybulewicz VL, et al. Preservation of long-term memory and synaptic plasticity despite short-term impairments in the Tc1 mouse model of Down syndrome. Learn Mem.2008; 15(7): 492-500.

34. Belichenko PV, Kleschevnikov AM, Masliah E, Wu C, Takimoto-Kimura R, Salehi A, et al. Excitatory-inhibitory relationship in the fascia dentata in the Ts65Dn mouse model of Down syndrome. J Comp Neurol.2009; 512(4): 453-66.

35. Korbel JO, Tirosh-Wagner T, Urban AE, Chen XN, Kasowski M, Dai $\mathrm{L}$, et al. The genetic architecture of Down syndrome phenotypes revealed by high-resolution analysis of human segmental trisomies. Proc Natl Acad Sci USA.2009; 106: 12031-6.

36. Prandini P, Deutsch S, Lyle R, Gagnebin M, Delucinge Vivier $\mathrm{C}$, Delorenzi M, Natural gene-expression variation in Down syndrome modulates the outcome of gene-dosage imbalance. Am J Hum Genet. 2007; 81:252-63.

37. Yahya-GraisonAit E, Aubert J, Dauphinot L, Rivals I, Prieur M, Golfier G, et al. Classification of human chromosome 21 gene-expression variations in Down syndrome: impact on disease phenotypes. Am J Hum Genet. 2007; 81(3):475-91.

38. Antonarakis SE, Lyle R, Dermitzakis ET, Reymond A, Deutsch S. Chromosome 21 and Down syndrome: from genomics to pathophysiology. Nat Rev Genet 2004; 5:725-38.

39. Wiseman FK, Alford KA, Tybulewicz VL, Fisher EM. Down syndrome--recent progress and future prospects. Hum Mol Genet. 2009;18(R1):R75-83.

40. Vilardell M, Rasche A, Thormann A, Maschke-Dutz E, Pérez-Jurado $\mathrm{LA}$, Lehrach $\mathrm{H}$, et al. Meta-analysis of heterogeneous Down Syndrome data reveals consistent genome-wide dosage effects related to neurological processes. BMC Genomics. 2011;12:229. 